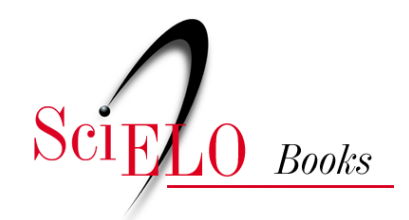

EDUFU

\title{
Pedagogia do jogo teatral uma poética do efêmero
}

\author{
Carmela Soares
}

\section{SciELO Books / SciELO Livros / SciELO Libros}

SOARES, C. Pedagogia do jogo teatral: uma poética do efêmero. In: FLORENTINO, A., and TELLES, N., eds. Cartografias do ensino do teatro [online]. Uberlândia: EDUFU, 2008, pp. 49-59. ISBN 978-85-7078-518-3. https://doi.org/10.7476/9788570785183.0006.

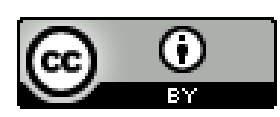

All the contents of this work, except where otherwise noted, is licensed under a Creative Commons Attribution 4.0 International license.

Todo o conteúdo deste trabalho, exceto quando houver ressalva, é publicado sob a licença Creative Commons Atribição $\underline{4.0}$.

Todo el contenido de esta obra, excepto donde se indique lo contrario, está bajo licencia de la licencia $\underline{\text { Creative Commons }}$ Reconocimento 4.0. 


\section{Pedagogia do jogo teAtral: UMA POÉTICA do EFÊMERO ${ }^{1}$}

Carmela Soares

Como professora de teatro do sistema municipal e estadual do ensino público do Rio de Janeiro, procuro refletir, neste estudo, sobre as possibilidades de se realizar na prática, especificamente dentro da grade curricular, uma ação pedagógica condizente com os princípios da linguagem teatral. Neste sentido, atribuo ao jogo teatral, papel central na formulação de uma pedagogia, que se propõe a desenvolver e estimular a educação estética do aluno.

A grande questão que se coloca em evidência é que função o jogo teatral ocupa na práxis pedagógica?

E ainda, como o jogo teatral permite ao aluno encontrar o gancho do prazer e reconhecer a natureza e o valor estético do conhecimento?

Portanto, de que maneira, dentro do caos da sociedade contemporânea e dentro do contexto escolar, o aluno ainda pode encontrar e dar significado à sua vida e às ações humanas? Segundo Carlos Byington ${ }^{2}$, o aprendizado escolar e o desenvolvimento do ser humano devem passar pela capacidade do indivíduo e da escola de criar símbolos e imagens significativas ou "estruturantes do self" - de si mesmo - como ele denomina.

A função principal destas imagens é a de apoiar (no sentido de sustentar) a formação de uma personalidade integrada com o todo, a partir da visão de unidade, e não de fragmentação, que tem prevalecido no mundo contemporâneo. Certamente, proporcionar aos alunos uma educação estética é um dos grandes desafios da sociedade atual, uma vez que ela está sofrendo, em escala gigantesca, os clichês, as imagens e os símbolos de memória curta que os meios de comunicação de massa multiplica e reproduz.

Encontramos, assim, no ato de levar o jogo teatral para a escola, um meio valioso de proporcionar ao aluno uma educação estética, fundada na experimentação, na relação sensível e direta com o espaço e com o outro, na produção e apreciação de formas e imagens teatrais, que lhe permitam experimentar e criar novos universos simbólicos, dotados de maior significação para sua vida.

\footnotetext{
${ }^{1}$ Este artigo teve origem a partir de minha dissertação de mestrado, intitulada Pedagogia do jogo teatral. SOARES, Carmela. Pedagogia do jogo teatral: uma poética do efêmero. O ensino do Teatro na Escola Pública. 2003. Dissertação (Mestrado) - Centro de Letras e Artes, Universidade Federal do Estado do Rio de Janeiro, Rio de Janeiro, 2003.

2 BYINGTON, Carlos Amadeu Botelho. Pedagogia simbólica: a construção amorosa do conhecimento do ser. Rio de Janeiro: Record: Rosa dos Tempos, 1996.
} 
Em sua natureza, o jogo teatral pressupõe a invenção e a reinvenção, a partir do vazio; dos jogos de corpos e do uso do espaço, nas condições em que se apresenta. E até mesmo da falta. Da falta de interesse dos alunos, da falta de escuta, da falta de comunicação, da falta de auto-estima e, principalmente, da falta de otimismo que caracteriza os jovens de nosso país, muitas vezes massacrados por uma realidade social, familiar e escolar, que os distancia de si mesmos e de seu poder e direito de expressão.

Partindo-se desta perspectiva, o jogo teatral é elevado à categoria de objeto estético, ou seja, possui uma elaboração formal e, enquanto tal, é produtor de uma teatralidade em sala de aula, que poderá ser reconhecida e apreciada à medida que o olhar do aluno, como também do professor, for trabalhado nesta direção.

Esta teatralidade, no entanto, tem características particulares ao contexto escolar e está sujeita a inúmeras variáveis. Seu aspecto é tênue, impreciso e manifesta-se em meio à profusão de corpos, gestos, sons, ruídos, num movimento de ordem e desordem, característico da sala de aula. Ela não se define como no teatro profissional, por seu alto grau de acabamento formal, mas, mesmo assim, pode ser reconhecida, enquanto forma expressiva dotada de qualidades estéticas.

Enquanto objeto estético, o jogo teatral comporta, em sua análise, dois elementos distintos e complementares: um elemento material e outro não material. Isto significa que, se por um lado, o jogo teatral pode ser reconhecido por suas características formais, isto é, por seu aspecto concreto, visível e sensível, possui também uma dimensão simbólica, ou seja, é da ordem do vivido, da experiência e, enquanto tal, é capaz de colocar o aluno em contato com o dentro e o fora de si mesmo. Assim, através de um substrato material próprio da linguagem teatral, podemos ver surgir, em sala de aula, imagens poéticas de grande significação para os alunos. Traduzidas em sensações, sentimentos, pensamentos e percepções interiores, estas imagens nascem da relação de troca entre o sujeito - jogadores e espectadores - e o objeto, ou seja, as formas sensíveis geradas no decorrer do próprio jogo.

Assim, a noção do objeto estético permite-nos reconhecer que o jogo teatral praticado em sala de aula comporta um sentido que pertence à própria esfera da experiência do teatro, compreendida como um acontecimento único, realizado no momento presente e dotado de uma carga expressiva capaz de despertar, no aluno, o conhecimento de si mesmo e do mundo.

Portanto, onde reside a beleza do jogo teatral realizado em sala de aula?

Segundo Duarte ${ }^{3}$, a beleza não é atributo ou propriedade que pertença ao sujeito ou ao objeto, mas se localiza nesta zona de encontro entre um e outro.

A beleza habita a relação. A relação onde os sentimentos entram em consonância com as formas que lhes tocam, vindas do exterior. O prazer estético reside na vivência da harmonia descoberta entre as formas dinâmicas dos sentimentos e as formas da $\operatorname{arte}^{4}$.

${ }^{3}$ DUARTE JÚNIOR, João Francisco. Fundamentos estéticos da educação. 2. ed. Campinas, SP: Papirus, 2000.

${ }^{4}$ DUARTE, 2000, p. 93. 
Da mesma maneira, a beleza do jogo teatral reside neste espaço intermediário entre sujeito e objeto, que Winnicott ${ }^{5}$ denomina de "espaço em potencial”. Segundo este autor, o jogo tem localização particular, ocorre num entre dois, não está nem dentro e nem fora do sujeito, mas se dá nesta relação de troca, de intercâmbio, entre sujeito e objeto, entre realidade e fantasia. É então, por meio do jogo, que o homem assume, em relação à realidade, uma postura ativa e dinâmica de transformação da mesma. Por conseguinte, é jogando que o homem atribui sentido e significado à vida. A realidade é, desta maneira, uma criação do indivíduo que joga. Aqueles que têm prejudicada sua "capacidade jogo" ou interação lúdica com a realidade, encontram-se num estado de total "submissão", de indiferenciação em relação a si mesmo e ao outro, o que termina por acarretar no indivíduo problemas de ordem psicológica.

O "espaço intermediário" característico do jogo, como define Winniccott ${ }^{6}$, é também o espaço da experiência estética, "o playground”, ou mais especificamente, "o campo de experimentação criativa da realidade", que permitirá ao bebê e, mais tarde, ao homem, em relação a este mundo, desenvolver um sentimento de pertencimento, de integração, de totalidade e, ao mesmo tempo, descobrir sua própria singularidade.

$\mathrm{Na}$ experiência estética com o jogo teatral, a consciência do aluno é lançada neste espaço intermediário, onde a percepção do objeto passa a ocorrer a partir de uma consciência mais expandida em que cabe aos sentimentos e às sensações, diferentemente, da consciência prática (no sentido de apenas conceitual, racional), orientar a relação sujeito-objeto, agora dentro de uma perspectiva de totalidade.

Ao conceber a noção de "espaço-vazio", inspirado no pensamento de diversas culturas, verificamos que Brook ${ }^{7}$ também nos remete à idéia do terceiro espaço, ou seja, do "espaço em potencial", definido por Winnicott. No "espaço-vazio", o sentimento de dualidade, provocado pela vivência de separação sujeito-mundo, é superado. O jogador, através de uma atitude lúdica, que comporta o inesperado, entrega-a ao momento presente, alcançaria uma área de silêncio que corresponderia à experiência do sagrado, do absoluto ou da totalidade, em que sujeito e mundo são percebidos como partes integrantes e, ao mesmo tempo, diferenciadas de uma mesma realidade.

Pela concepção do "espaço vazio", as ações cênicas não estariam restritas ou limitadas a construções mentais, mas surgiriam de dentro de um espaço interior amplo, aberto, enraizado. A partir deste espaço, não é preciso "fazer nada”, não é necessário "pensar em nada": toda ação nasce espontaneamente da completa presença e disponibilidade do ator em cena. Quando o ator alcança este espaço, ele está totalmente imerso num estado criativo. Não recorre a clichês ou a ações mecânicas como forma de expressão, mas é capaz de se colocar aberto e sem medo, diante das incertezas que este lugar provoca.

Para $\mathrm{Brook}^{8}$, no teatro, a intensa atividade mental que dirige as ações humanas, principalmente do homem ocidental, a partir do espaço-vazio, cede lugar à vivência de uma experiência sensível e direta com a realidade cênica e, portanto, mais

\footnotetext{
${ }_{5}$ WINNICOTT, Donald Woods. O brincar e a realidade. Rio de Janeiro: Imago, 1975. p. 71.

6 WINICOTT, 1975.

7 BROOK, Peter. A porta aberta: reflexões sobre a interpretação e o teatro. Tradução Antônio

Mercado. 2. ed. Rio de Janeiro: Civilização Brasileira, 2000. p. 19.

${ }^{8}$ BROOK, 2000.
} 
autêntica e viva. Por isso, mais do que um espaço físico despojado, "o espaço-vazio" consiste numa disponibilidade interna de se dar ao jogo, que gera, por sua vez, a capacidade de reconhecer a beleza que permeia as relações e as formas.

$\mathrm{Na}$ escola pública, podemos perceber que grande parte dos alunos vive o desafio de existir verdadeiramente, ou seja, de superar o estado de "submissão" ou esquecimento a que muitos estão sujeitos. Encontramos, pois, no jogo teatral uma possibilidade de despertar o aluno para este "espaço-vazio", para este "espaço em potencial”, autêntico, criativo em cada um.

Para compreendermos a experiência de beleza proporcionada pelo jogo teatral em sala de aula, é importante recorrermos também às idéias de Huizinga a a respeito do jogo. Huizinga aproxima o jogo do domínio da estética ao esclarecer que ele produz ordem e é ordem. "Os laços que unem o jogo e a beleza são muitos e bem íntimos. Em suas formas mais complexas, o jogo está saturado de ritmo e harmonia, que são os mais nobres dons de percepção estética de que o homem dispõe". Descrevendo as qualidades formais do jogo, ele destaca: a intensidade, a tensão ou a incerteza, o prazer, o divertimento, a atividade voluntária, o caráter desinteressado do jogo, sua delimitação em limites de espaço e tempo, a criação de uma realidade paralela diferente da vida habitual, o caráter fictício ou representativo, a sujeição do jogo a certas regras.

Da mesma maneira, o jogo teatral na escola pode ter sua beleza reconhecida, quando realizado dentro de um clima de alegria, intensidade, prazer e tensão; quando obedece às regras propostas pelo professor ou pelo grupo ou, ainda, quando reinventa outras; quando tem caráter livre e não é imposto; quando instaura uma realidade cênica diferente da vida cotidiana; quando tem sua área de jogo delimitada ou enquadrada e quando, pela imaginação, cria inúmeras imagens e metáforas decorrentes de um processo contínuo de simbolização.

De acordo com o conceito de jogo proposto por Huizinga ${ }^{10}$, podemos afirmar que o jogo teatral, enquanto objeto estético, possui uma estrutura ou realidade independente, autônoma, portadora de sentido próprio, configurada no decorrer do próprio jogo, pela manipulação de uma materialidade específica ao fazer teatral. Isto significa que, por meio do jogo, os elementos materiais do teatro como texto, espaço, personagem, gesto, som, movimento, corpo, serão organizados, ativa e dinamicamente, dentro de uma linguagem, de uma estrutura significante que garantirá à cena a criação de uma forma expressiva, ou seja, de uma teatralidade.

Dessa maneira, o jogo teatral deixa de ser um simples exercício, a ilustração de um tema ou mesmo um mero momento de brincadeira e se define como uma experiência estética. Experiência que surge pela interação imediata do sujeito com o objeto confeccionado no momento presente e que é, portanto, dinâmico e efêmero, mas sobretudo vivo e pulsante.

Por este motivo, encontramos na textura viva do jogo teatral, a própria essência e característica fundamental do objeto estético. Na sua intensidade, o jogo teatral realizado em sala de aula apresenta um sentido de ordenação, ritmo e harmonia e, enquanto tal, resulta num todo orgânico, vivo, expressivo, capaz de lan-

\footnotetext{
${ }_{9}$ HUIZINGA, Johan. Homo Ludens: o jogo como elemento da cultura. 4. ed. São Paulo: Perspectiva, 1996. p. 10.

${ }^{10}$ HUIZINGA, 1996. 
çar jogador e espectador numa experiência de troca e de partilha. Nesse momento, podemos perceber, em meio ao movimento de corpos, ruídos e sons característicos da aula de teatro no ensino público, o traçado de pequenos desenhos cênicos, isto é, de "pequenas formas", pequenos momentos de criação. Estas pequenas formas estão fortemente determinadas pelos valores expressivos da contemporaneidade, uma vez que a falta de sentido do mundo atual e o aspecto desarmônico das estruturas sociais resultaram na criação de uma linguagem teatral em que o fragmento e a descontinuidade predominam, enquanto qualidades estéticas e formais.

Por conseguinte, as imagens criadas no decorrer da aula de teatro nem sempre são nítidas ou totalmente delineadas. Podemos compará-las a um borrão no papel, onde as formas se esboçam, mas não se desprendem totalmente, imagens trançadas num tempo ínfimo, num segundo, mas, assim mesmo, com poderes de encantamento e formadoras de memória.

À semelhança com o teatro contemporâneo, podemos verificar que o jogo teatral realizado em sala de aula produz imagens independentes, flashes, superposições, que um olhar atento e bem treinado poderá captar. Deste modo, basta trabalhar sobre esta forma expressiva, dar-lhe dimensão, acentuar seu aparecimento e desaparecimento, mostrar sua existência e as maneiras como dela podemos dispor, intencionalmente, no ato da comunicação teatral.

A comunicação dentro da escola ocorre nesta dimensão múltipla do olhar, característica do teatro e do mundo contemporâneo. Um olhar que já não abarca o todo como no teatro renascentista, época em que o homem é colocado no centro do espaço e, a partir daí, relaciona-se com a natureza e com o mundo ao seu redor. O olhar contemporâneo tem a visão dos fragmentos que compõem este todo, a sua superfície, virtualidade e desdobramentos, como nos lembra Fayga Ostrower ${ }^{11}$.

A ocupação desordenada do espaço feita pelos alunos ao entrarem em sala de aula, a profusão de movimentos, uma guerra de papel, o repicar do sino da igreja ao lado, o chão cobertos de folhas de amendoeiras podem transformar-se em motivo de jogo. Tudo pode ser usado para aprender a linguagem do teatro: seus elementos, climas, tons, a importância de um objeto no espaço, a força expressiva do silêncio, o significado do "espaço-vazio" que comporta o gesto, o olhar e suas inúmeras representações. Trata-se, portanto, de identificar, no cotidiano da escola e da vida, a presença de uma materialidade específica ao fazer teatral, que não está restrita apenas ao domínio do texto e do diálogo. Deste modo, antes mesmo de qualquer tentativa de teatralização da cena, que muito freqüentemente leva à aplicação mecânica dos códigos teatrais, é importante direcionar o olhar do aluno, como nos faz recordar Ryngaert $^{12}$, para os elementos de teatralidade, involuntários, advindos do lugar real.

A perspectiva é de que os alunos possam identificar os elementos de teatralidade manifestos espontaneamente, como também sejam capazes de incorporá-los, progressivamente, dentro do campo da ação cênica propriamente dita. Assim, um espaço, um gesto, um balançar de árvores, uma mudança de luminosidade, o barulho repentino da chuva, tudo pode ser tomado pelos alunos, durante o jogo teatral, como signos concretos de uma teatralidade. Dessa maneira, o aluno aprende,

${ }_{11}$ OSTROWER, Fayga. Criatividade e processo de criação. Petrópolis: Vozes, 1999.

12 RYNGAERT, Jean-Pierre. Jouer, représenter: pratiques dramatiques et formation. Paris: Cedic, 1985. p. 60. 
paulatinamente, que o jogo é um campo aberto, enriquecido pelos signos, que se constituem no decorrer da própria ação e não um campo fechado, determinado por convenções rígidas e transpostas mecanicamente para o seu interior.

$\mathrm{Na}$ sala de aula, buscamos estimular a entrada do aluno no jogo, como também refletir e analisar a dinâmica de criação das imagens: sua organização formal, suas cores, intensidade, movimento ou a maneira como se desenham no espaço. $\mathrm{O}$ objetivo é desenvolver o olhar intencionado, o olhar consciente sobre as formas dimensionadas no espaço, ampliando a experiência sensível dos alunos em torno das qualidades estéticas do jogo teatral e, por conseguinte, tornando possível o desdobramento do seu campo de significação.

Dentro do contexto rude e antiestético, característico da escola pública, pensar uma "poética do efêmero", como proposta metodológica para o ensino do teatro, torna-se fundamental. Por meio do jogo teatral, procuramos articular, dentro de um todo significativo para os alunos, as imagens que se esboçam, ainda que de maneira fragmentada e inacabada, no cotidiano escolar e da vida.

Assim, mesmo que as condições do ensino público não sejam as mais adequadas, tentamos superar as dificuldades tirando partido da situação concreta que se apresenta em sala de aula, através do reconhecimento e da exploração dos signos e da materialidade dos códigos teatrais.

Por este motivo, a noção do jogo teatral, enquanto objeto estético, permite-nos reconhecer na escola, em meio à sua rotina diária, a confecção e a leitura de uma teatralidade que, mesmo marcada por uma tessitura efêmera, está carregada de beleza e poesia. A partir desta perspectiva, encontramos na formulação de uma pedagogia do jogo teatral como poética do efêmero, a possibilidade concreta de ensinar e de aprender teatro na escola pública, segundo os princípios da linguagem teatral.

Consideramos fundamental, no entanto, destacar e analisar a função de dois elementos pedagógicos importantes para a realização deste objetivo. São eles: o olhar e o espaço. Estes dois elementos estão inter-relacionados. Neste sentido, o olhar é trabalhado em função de um espaço enquadrado, ou seja, à medida que um determinado espaço é delimitado, o olhar sobre este espaço é intensificado. Isto é, torna-se mais consciente, focado, interessado sobre as formas, movimentos, objetos e sentimentos estruturados no decorrer do próprio jogo. O olhar ganha, então, uma qualidade nova: deixa de ser um olhar prático e utilitário, para, agora, assumir uma dimensão estética. Desta maneira, pelo enquadramento do espaço, o olhar, sobre este mesmo espaço, modifica-se, passando a ser percebido ou vivenciado no seu elemento de beleza. Esta é, portanto, a magia do jogo teatral na sala de aula. Por seu intermédio, os alunos transformam o espaço institucional em espaço lúdico, em espaço poético.

Segundo Stanislavski13, o olhar está na base do jogo teatral: "É essencial nos reeducarmos para olhar e ver no palco, para escutar e ouvir".

Diante deste princípio, Stanislavski ${ }^{14}$ desenvolveu um recurso didático, cuja função é auxiliar o aluno a concentrar a atenção no espaço da cena, isto é, na-

13 STANISLAVSKI, Constantin. A preparação do ator. Tradução Pontes de Paula Lima. 17. ed. Rio de Janeiro: Civilização Brasileira, 2001. p. 112.

14 STANISLAVSKI, 2001. 
quilo que acontece na esfera do jogo teatral. Ao trabalhar sobre os "círculos de atenção", que correspondem a enquadramentos espaciais diferenciados, pequeno, médio e grande, o aluno estabelece um foco de atenção em relação aos objetos colocados mais próximos ou mais distantes dele. Ao realizar tal objetivo, ao se colocar de forma atenta na relação com o espaço do jogo, o desconforto de atuar diante de uma platéia é superado, ampliando-se a consciência do aluno em relação aos elementos necessários à criação da realidade cênica.

Neste estado de atenção concentrada, o aluno, de acordo com Stanislavski ${ }^{15}$ tem sua percepção estética ampliada, pois intensifica a relação com o espaço ao redor e com os elementos necessários à criação da realidade cênica. Desta forma, percebe os objetos nos seus detalhes mais intricados e, ao mesmo tempo, entra em contato com as variações e os matizes dos seus sentimentos e pensamentos.

Outro aspecto importante da teoria dos “círculos de atenção" é a perspectiva de que o olhar, direcionado dentro de um espaço delimitado, leva o aluno à ação. Ao entrar na relação com o objeto, através da observação, o aluno é movido a agir e agindo descobre novos aspectos do mesmo objeto, expandindo o seu campo de percepção, como se pode verificar através das palavras de Stanislavski:

A observação intensiva de um objeto naturalmente desperta o desejo de fazer com ele alguma coisa. Fazer qualquer coisa com ele intensifica, por sua vez, a observação do mesmo. Essa inter-relação mútua estabelece um contato mais forte com o objeto da atenção de vocês ${ }^{16}$.

Partindo deste princípio, o espaço pode ser considerado o elemento fundador do jogo teatral. $\mathrm{Na}$ escola, podemos verificar que o procedimento prático de enquadrar os espaços ajuda o aluno a vencer a resistência inicial de se colocar em jogo. O espaço funciona, assim, como um elemento concreto que estimula a ação e a exploração sensível. Desta maneira, o espaço apresenta-se como um convite de entrada ou como um elemento facilitador do jogo.

O procedimento metodológico de diferenciar o "espaço do jogo" do "espaço do não jogo" possibilita também aos alunos irem fazendo, de modo progressivo, a passagem entre a simples brincadeirinha e a experiência teatral. Ao entrar e sair de um espaço definido, aos poucos, eles começam a perceber que a ação no teatro se dá segundo regras e convenções específicas, diferentes da realidade. Nesse momento, o jogo deixa de ser sinônimo de "bagunça”, "maluquice” e a simples diversão em sala de aula ganha um novo estatuto, o jogo passa, então, a ser chamado de improvisação, cena, teatro.

Por conseguinte, a delimitação de uma área de jogo coloca o olhar dos alunos sob perspectivas diferentes, ora assumindo o lugar dos jogadores, ora dos espectadores. É, pois, através deste jogo de olhares, que o fenômeno teatral passa a existir, como nos revela Pavis, ao definir o significado da palavra grega theatron:

A origem grega da palavra teatro, o theatron, revela uma propriedade esquecida, porém fundamental, desta arte: é o local de onde o público olha uma ação que lhe é

${ }^{15}$ STANISLAVSKI, 2001.

16 STANISLAVSKI, 2001, p. 111. 
apresentada em outro lugar. O teatro é mesmo, na verdade, um ponto de vista sobre um acontecimento: um olhar, um ângulo de visão e raios ópticos o constituem. Tão somente pelo deslocamento do olhar e objeto olhado é que ocorre a construção onde tem lugar a representação ${ }^{17}$.

Por esse motivo, Ryngaert ${ }^{18}$ ressalta que a prática do jogo no ensino do teatro deve levar em consideração o lugar de onde se vê e o lugar de onde se é visto. Neste sentido, é importante colocar o olhar dos alunos em relação ao espaço do jogo, levá-los a observar e a perceber o espaço, antes, durante e depois do jogo; levá-los a compreender e a analisar as imagens que dali surgiram, a sua textura e a maneira como foram elaboradas.

$\mathrm{Na}$ prática, observamos, portanto, que o enquadramento do espaço estimula o aluno a enfrentar os riscos inerentes ao "espaço-vazio", intensifica a atenção do grupo e prepara internamente os jogadores para apreender o espaço em suas possíveis relações estéticas. Marca, portanto, a entrada do aluno num círculo mágico, diferente do habitual. Lembremos, também, que para Huizinga ${ }^{19}$, a criação de um círculo mágico é um dos elementos formais do jogo, que nos permite reconhecê-lo no seu caráter estético. Dessa maneira, o jogo ocorre dentro de um espaço-tempo, que lhe é específico. Por sua vez, Oberlé20 chama nossa atenção para o fato de o espaço ser um elemento estruturante do próprio jogo, propondo o seguinte paradoxo: "Jogar implica a existência de um espaço, um espaço diferente da realidade; mas é apenas jogando que este espaço se constitui. ${ }^{21}$ "

Assim, se por um lado, o espaço permite o surgimento do próprio jogo, por outro lado, é também um elemento significante e, enquanto tal, está repleto de sentido. Neste aspecto, Ryngaert ${ }^{22}$ esclarece: "Os espaços institucionais onde circulamos estão carregados de sentido pelos que neles vivem ou trabalham. É bem interessante esvaziar esse sentido e ter o prazer em todos os cruzamentos de sentido que aparecem. O jogo é um meio de recarregar os espaços”.

Por meio do jogo teatral, podemos desdobrar o significado original de um mesmo espaço, e propor inúmeras imagens e leituras. Os alunos se surpreendem e se divertem ao perceberem as possibilidades de invenção e reinvenção de um mesmo espaço, a partir de sua própria imaginação. Desta maneira, iniciamos o trabalho prático, delimitando uma área de jogo, depois explorando com o corpo sua geografia, volumes, distâncias, aberturas, reentrâncias, luminosidade, criando a partir daí novas metáforas. Assim, de um mesmo espaço, surge um confessionário, uma casa de detenção, uma cadeira de rodas, uma carruagem e, portanto, deste modo, o aluno percorre um trajeto pedagógico que vai do plano real, físico, para o plano imaginário, estabelecendo o "espaço poético", que pode ser definido, segundo Lessa ${ }^{23}$, como o encontro destes dois espaços: o real e o imaginário.

Buscando descobrir espaços de aprendizagem e do fazer teatral "não-convencionais" ou "não-tradicionais", percorremos com os alunos os diversos espaços da

\footnotetext{
17 PAVIS, 1999, p. 372.

1 RYNGAERT, 1985.

19 HUIZINGA, 1996.

20 OBERLÉ DOMINIQUE. Jeu dramatique et développement personnel. Paris: Retz, 1989. p. 49.

21 Tradução livre.

22 RYNGAERT, 1985, p. 71.

23 Cf.: LESSA, Bia (Org.). Conbecimento teatral. 1985. Apostila mimeografada.
} 
sala de aula, da escola, do bairro e de outras localidades, conferindo-lhes maior sentido e humanidade. Encontramos na perspectiva de jogar, em espaços "não-tradicionais” (a sala de aula) uma ação pedagógica de extrema riqueza e importância. Esta ação auxilia a romper com uma condição de confinamento, a que estão submetidos os alunos na escola; propõe uma atitude dinâmica e ativa diante do conhecimento; aumenta a proximidade entre professor e aluno; questiona as relações de saber e poder, características do ensino tradicional; suscita uma experiência de prazer e de liberdade junto ao espaço e nos permite superar o espaço atravancado de carteiras.

O jogo teatral está dotado de grande significação para o ensino do teatro na escola pública, principalmente nos grandes centros urbanos, onde a falta se faz presente em todos os sentidos, seja na carência de condições físicas, seja no crescente empobrecimento humano, social e político com que nos deparamos constantemente.

Uma outra questão que se levanta ao analisar o elemento espaço para a construção de uma pedagogia do jogo é que ele nos permite aproximar o ensino do teatro na escola aos princípios do jogo teatral contemporâneo, de modo diferente de um teatro tradicional, em que há o predomínio do texto e do diálogo. O jogo teatral na atualidade privilegia o espaço como substrato concreto, onde se articulam todos os demais signos da linguagem teatral. Assim, a teatralidade é construída no espaço direto da cena e, desta maneira, a palavra passa a ser mais um dos elementos significantes da linguagem e não o único. O teatro é, portanto, a linguagem do espaço, é "poesia no espaço", como nos recorda Artaud"2.

Sendo assim, é preciso, na sala de aula, "penetrar o espaço", ocupá-lo dinamicamente para a criação da realidade cênica. É o que Spolin ${ }^{25}$ chama de "físicalização", ou seja, é pela experimentação sensível e orgânica do corpo no espaço que o aluno irá apreender os diversos signos da linguagem teatral e suas possíveis relações. Neste sentido, podemos dizer que a teatralidade enquanto forma expressiva, contemporânea, inscreve-se no espaço. Ela emerge das relações que os alunos estabelecem no espaço, física e concretamente, a partir da relação direta com os colegas e com o ambiente no próprio momento do jogo.

Podemos verificar que por meio das brincadeiras do corpo no espaço, do correr, do saltar, do esconder, a criança começa, desde bem pequena, a organizar seus primeiros desenhos ou composições cênicas. Segundo Slade ${ }^{26}$, o aprendizado do teatro tem início com "o jogo pessoal”, através do qual a criança se lança no espaço, percebendo-o em sua tridimensionalidade, geografia e distâncias e, ainda, inventando personagens e consequentemente espaços de representação. Ela vai, aos poucos, adquirindo noções de profundidade, tamanho, volume e eqüidistância, ou seja, começa a estabelecer relações formais a partir do próprio espaço. O objetivo do jogo teatral na escola é, portanto, retomar esta primeira experiência de liberdade da criança no espaço, agora apreendida e elaborada de uma maneira consciente e expressiva. Deste modo, a construção da teatralidade na escola consiste em desenvolver, no aluno, este olhar progressivamente consciente, tornando cada gesto e

${ }^{24}$ ARTAUD, Antonin. O teatro e seu duplo. Tradução Teixeira Coelho. 2. ed. São Paulo: M. Fontes, 1999. p. 37.

${ }^{25}$ SPOLIN, Viola. Improvisação para o teatro. Tradução Ingrid Dormien Koudela. São Paulo: Perspectiva, 1982. p. 15.

26 SLADE, Peter. O jogo dramático infantil. Tradução Tatiana Belinky. São Paulo: Summus, 1978. p. 17. 
cada ação no espaço, intencional.

É também pela ocupação e exploração do espaço que o aluno progressivamente descobre e conquista o seu próprio espaço pessoal. Assim, no início do curso de teatro, aquele espaço que se mostrava ameaçador, "grande" (como se refere um dos alunos), torna-se paulatinamente "pequeno", acolhedor; ele é enfim conquistado. O espaço do jogo não é mais fonte de medo, mas de prazer. A timidez dá lugar ao enorme desejo de jogar. As tendências exibicionistas do jogador são substituídas pelo sentido do coletivo, pelo reconhecimento da troca e da parceria mútua. O espaço passa, então, a ser "lugar" de identidade e de relação do sujeito com o mundo, a partir do qual se constrói uma história, como define Augée ${ }^{27}$.

Por sua vez, a questão da valorização do espaço no teatro contemporâneo coloca o ator num lugar de importância dentro do processo criativo, uma vez que há uma retomada da improvisação e do jogo. Neste momento, segundo Ryngaert ${ }^{28}$, “o corpo do ator passa a ser encarado como fonte de invenção". O ator não fica mais preso apenas às indicações do diretor, mas tem autonomia, experimenta, pesquisa, faz valer suas idéias e percepções da cena.

Da mesma maneira, a prática do jogo teatral permite ao aluno realizar seu potencial criativo e reafirmar seu lugar de sujeito dentro da escola e do mundo. Ao assumir uma postura ativa e dinâmica, a realidade deixa de ser apreendida como um dado acabado, imutável e passa a ser construída e transformada pela ação particular e coletiva dos próprios alunos que, cada vez mais, apropriam-se de suas ações e palavras. Esta atitude lúdica estimula, nos alunos, o conhecimento sensível e, portanto, estético da vida. Encontram, deste modo, em meio a um cotidiano árido, uma tessitura delicada e poética, capaz de conferir novo sentido às suas vidas.

Portanto, a noção do jogo teatral, enquanto objeto estético, permite-nos colocar no centro do processo de ensino-aprendizagem do teatro a questão da teatralidade, sua criação e leitura, no cotidiano da escola. Desta maneira, podemos afirmar que é através da linguagem, de sua materialidade, que o aluno poderá alcançar, de maneira mais profunda, o sentimento de transcendência, de integração, de harmonia, de forma e beleza, que deveria reger a educação e a vida, em todos os seus momentos.

27 AUGÉ, Marc. Não lugares: introdução a uma antropologia da supermodernidade. Tradução Maria Lúcia Pereira. 2. ed. Campinas, SP: Papirus, 2001. p. 50.

${ }^{28}$ RYNGAERT, 1985, p. 46. 


\section{REFERÊNCIAS}

ARTAUD, Antonin. O teatro e seu duplo. Tradução Teixeira Coelho. 2. ed. São Paulo: M. Fontes, 1999.

AUGÉ, Marc. Não lugares: introdução a uma antropologia da supermodernidade. Tradução Maria Lúcia Pereira. 2. ed. Campinas, SP: Papirus, 2001.

BROOK, Peter. A porta aberta: reflexões sobre a interpretação e o teatro. Tradução Antônio Mercado. 2. ed. Rio de Janeiro: Civilização Brasileira, 2000.

BYNGTON, Carlos Amadeu Botelho. Pedagogia simbólica: a construção amorosa do conhecimento do ser. Rio de Janeiro: Record: Rosa dos Tempos, 1996.

DUARTE JÚNIOR, João Francisco. Fundamentos estéticos da educação. 2. ed. Campinas, SP: Papirus, 2000.

HUIZINGA, Johan. Homo Ludens: o jogo como elemento da cultura. 4. ed. São Paulo: Perspectiva, 1996.

OBERLÉ DOMINIQUE. Jeu dramatique et développement personnel. Paris: Retz, 1989.

OSTROWER, Fayga. Criatividade e processo de criação. Petrópolis: Vozes, 1999.

PAVIS, Patrice. Dicionário de teatro. São Paulo: Perspectiva, 1999.

RYNGAERT, Jean-Pierre. Joner, représenter: pratiques dramatiques et formation. Paris: Cedic, 1985.

SLADE, Peter. O jogo dramático infantil. Tradução Tatiana Belinky. São Paulo: Summus, 1978.

SOARES, Carmela. Pedagogia do jogo teatral: uma poética do efêmero. O ensino do Teatro na Escola Pública. 2003. Dissertação (Mestrado) - Centro de Letras e Artes, Universidade Federal do Estado do Rio de Janeiro, Rio de Janeiro, 2003.

SPOLIN, Viola. Improvisação para o teatro. Tradução Ingrid Dormien Koudela. São Paulo: Perspectiva, 1982.

STANISLAVSKI, Constantin. A preparação do ator. Tradução Pontes de Paula Lima. 17. ed. Rio de Janeiro: Civilização Brasileira, 2001.

WINNICOTT, Donald Woods. O brincar e a realidade. Rio de Janeiro: Imago, 1975. 